\title{
USO DE IMÁGENES SATELITALES DE ALTA RESOLUCIÓN PARA GENERAR CARTOGRAFÍA
}

\author{
Patricio Zavala O. ${ }^{1} \quad$ Carlos Zavala A. $^{2}$ \\ Recibido el 29 de noviembre de 2001, aceptado el 23 de julio de 2002
}

\begin{abstract}
RESUMEN
Se presenta la metodología aplicada en la ciudad de Arica, Norte de Chile, para generar cartografía de altura de construcciones, mediante el análisis digital de una imagen satelital de alta resolución. Para ello, nos basamos en el cálculo de la longitud de las sombras que se derivan de distintas edificaciones, y del azimut solar de una imagen IRS 1C, que fue remuestreada mediante convolución cúbica a 5 metros.

Este trabajo está basado fundamentalmente en los logros alcanzados en el desarrollo de la tesis doctoral de uno de los autores (1), y que se refirió al análisis de vulnerabilidad sísmica mediante técnicas de Sistema de Información Geográfico (S.I.G.) y Teledetección.

Los resultados logrados creemos permitirán obtener cartografía resultante, que esperamos sea útil para la gestión territorial a nivel intraurbano.
\end{abstract}

Palabras Claves: Teledetección, S.I.G., construcciones

\begin{abstract}
This paper describes the methodology used, to generate building height cartography, through the analysis of high resolution satellite images of the city of Arica, in northren Chile. Calculations were made using shadow lengths, derived from different constructions, and from the solar azimuth of an IRS image $1 C$, that was processed by cubic convolution at 5 meters.

This research project is based on the development of the doctoral thesis of one of the authors (1), related to the analysis of seismic vulnerability using Geografical Information System (G.I.S) technology and remote sensing techniques. The results of this project will yield cartography, that we hope will be useful for urban territorial management.
\end{abstract}

Keywords: Remote sensing, G.I.S., buildings

\section{INTRODUCCIÓN}

En los últimos 10 años, la bibliografía de gestión de riesgos naturales ha señalado a la vulnerabilidad, como la variable a intervenir en la disminución de un riesgo natural específico, la que según Blaikie puede ser entendida como "las características de individuos o grupos de personas, en términos de su capacidad de anticipar, enfrentar, resistir, y recuperarse del impacto de un peligro natural. Involucra una combinación de factores determinados por su nivel de vida, que los exponen a un riesgo" [1]. En el caso sísmico, ésta puede ser definida como la capacidad de respuesta de la población ante la presencia de un sismo. Por ello, y siguiendo la idea de Seaman (1984), las características específicas de construcción de viviendas y edificios, deben necesariamente ser incorporados en todo estudio de vulnerabilidad sísmica, destacando entre ellas las alturas de las construcciones como una variable de fragilidad constructiva [2].

Desde la perspectiva de la gestión del riesgo sísmico, lo que interesa es poder disponer de información intraurbana, confiable y actualizada, la que no siempre está disponible para este tipo de estudios. Ante esta necesidad, en los últimos años ha ido aumentando el uso de imágenes de satélite en estudios urbanos. Sin embargo, uno de los problemas fundamentales que tenían estas imágenes, estaba relacionado con la resolución espacial que poseían, ya que los objetos

\footnotetext{
${ }^{1}$ Universidad de Tarapacá, Departamento de Antropología, Geografía e Historia, Arica - Chile, pzavala@uta.cl

${ }^{2}$ Ingeniero mecánico, czavala@entelchile.net
} 
urbanos eran a menudo inferiores al tamaño que cubría un píxel de una imagen, lo que se refleja en un efecto de alisamiento de la misma, y en la pérdida de información. A pesar de ello, y del hecho de que los fenómenos urbanos presentan firmas espectrales muy similares, éstos podían ser identificados gracias a las diferencias notorias que manifiestan en sus características geométricas [3].

A partir del año 1972, fecha en que se comenzaron a recibir imágenes del sensor $M S S$ del satélite Landsat, se comenzaron a aplicar técnicas de teledetección en áreas urbanas, las que si bien, han sido discretas, como consecuencia de la pobre resolución espacial y espectral de los datos, fueron aumentando conforme al mejoramiento de la resolución espacial de las imágenes de los sensores Landsat TM y Spot HRV [4].

La puesta en órbita de sensores de alta resolución espacial como Ikonos, Orbimage, e IRS, entre otros, está permitiendo aumentar y mejorar la información obtenida por teledetección, aspecto que se puede apreciar en Fig. 1 , en donde se comparan dos ventanas de la ciudad de Arica, del sector Ex Estadio y Regimiento Rancagua, de una imagen Landsat $T M$ y de la imagen $I R S 1 \mathrm{C}$, ya corregida geométricamente.

En este contexto se ubica este trabajo, que pretende exponer una metodología para generar cartografía de alturas, mediante el análisis de imágenes pancromáticas de alta resolución.

\section{Generación de información base}

Con el objeto de acceder a información inaccesible mediante otros medios tradicionales, se adquirió una imagen del satélite IRS 1C, en modo Pancromático, del 18 de marzo del año 2.000, que posee una resolución espacial que responde a los requerimientos de este trabajo (5.8 metros, que luego fue remuestreada a 5 metros).

Esta imagen se encontraba corregida mediante 5 puntos de control, a través de la técnica del vecino más cercano (nearest neighbour), que sitúa en cada celdilla de la imagen corregida el nivel digital (ND) del píxel más cercano de la imagen original. Sin embargo, al cotejarla con puntos conocidos, se encontró que estaba notoriamente desplazada, y que su calidad visual era bastante deficiente, debido a que la técnica de corrección ya señalada, tiene como inconveniente, la distorsión que origina en rasgos lineales de la imagen [5]. Por este motivo, y con el objeto de obtener una mayor calidad desde el punto de vista visual, se procedió a corregirla geométricamente mediante la técnica de convolución cúbica, que considera los niveles digitales (ND) de los 16 píxeles más próximos, y que tiene como característica fundamental el mejorar visualmente los elementos geométricos (lineales) de una imagen, aspectos que son de interés para este trabajo.

\section{Landsat TM (30 metros)}

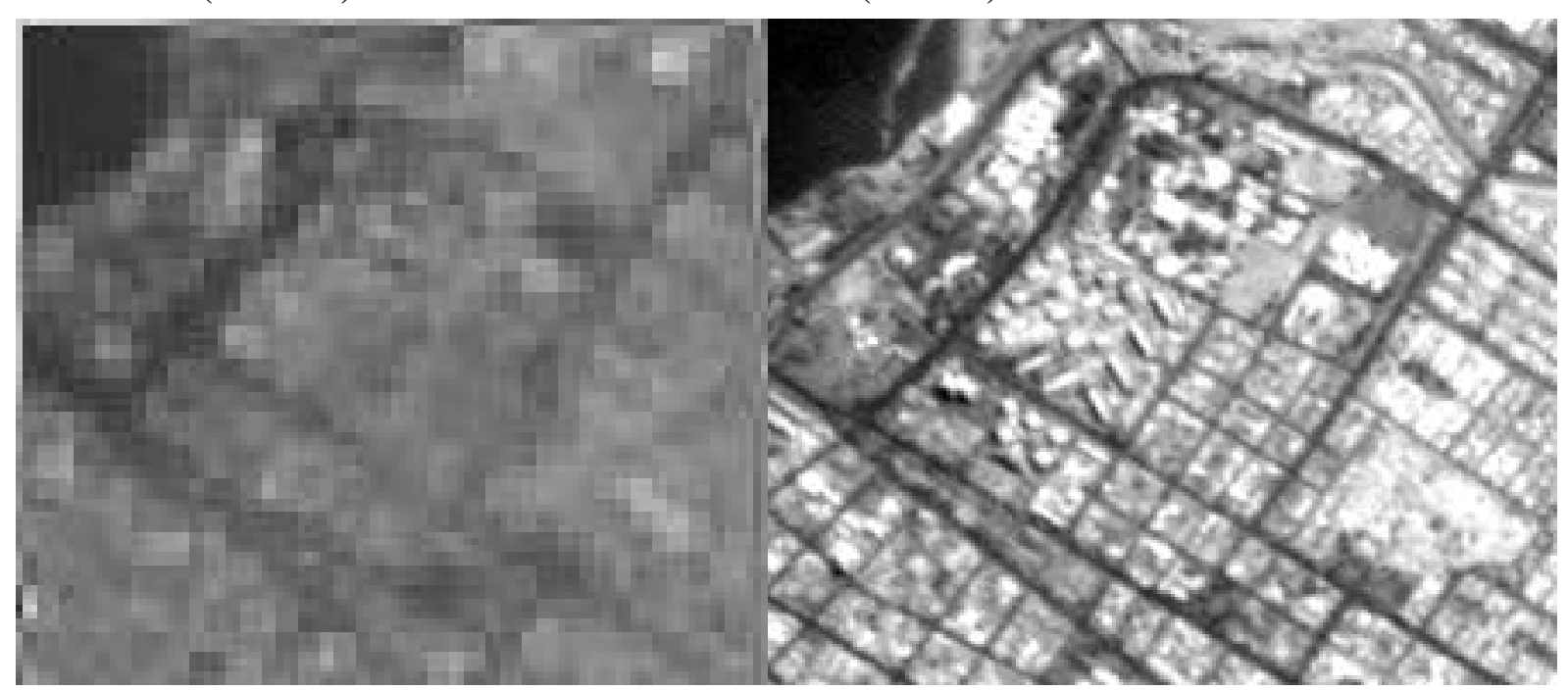

Fig.1.- Comparación de resolución espacial entre imágenes Landsat TM e Irs 
Uso de imágenes satelitales de alta resolución para generar cartografía

Para ello se hizo uso de 87 puntos de control, obtenidos previamente mediante un equipo GPS Trimble Explorer (2 metros de resolución), de las instalaciones que se consideraron como críticas, y de elementos geométricos de clara identificación, como esquinas de calles conocidas. La proyección utilizada fue la UTM, centrada en la zona $19 \mathrm{~K}$ Sur, con el elipsoide de referencia $W G S$ 84, dando como resultado un $R M S$ total de 5.82 (error medio cuadrático)

Los puntos utilizados en la corrección, se pueden apreciar en la Fig. 2, mientras que sus coordenadas se presentan en la tabla 1, donde es factible observar las coordenadas originales, las generadas, los puntos omitidos (en negrillas) y los residuales producto de la corrección aplicada.

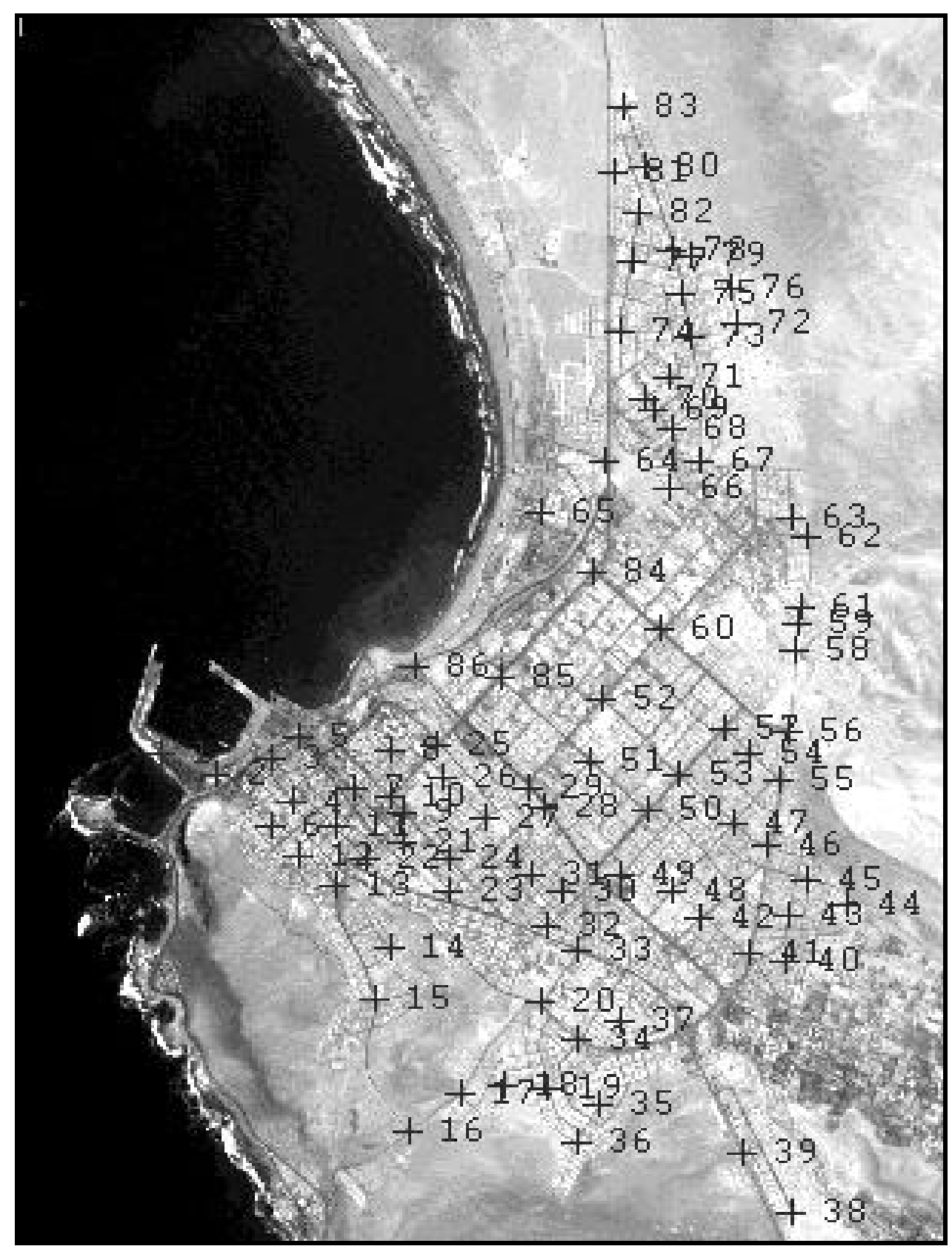

Fig. 2.- Puntos de control de la corrección geométrica 
Patricio Zavala O., Carlos Zavala A.

Tabla 1.- Matriz de puntos de control

\begin{tabular}{|c|c|c|c|c|c|}
\hline Puntos & $\mathrm{X}$ original & Y original & $\mathrm{X}$ corregido & Y corregido & Residual \\
\hline 1 & 360869.4 & 7956584 & 360807 & 7956911.54 & 15.4 \\
\hline 2 & 361003.4 & 7956191 & 360959.072 & 7956549.06 & 5.39 \\
\hline 3 & 361054.7 & 7956758 & 361011.495 & 7957076.98 & 15.35 \\
\hline 4 & 360826.1 & 7955917 & 360785.223 & 7956326.22 & 9.73 \\
\hline 5 & 361441.1 & 7956346 & 361409.44 & 7956657.24 & 0.59 \\
\hline 6 & 361709.2 & 7956727 & 361672.977 & 7956969.08 & 16.98 \\
\hline 7 & 361784.1 & 7956131 & 361772.323 & 7956441 & 10.67 \\
\hline 8 & 361685.5 & 7956299 & 361673.421 & 7956587.12 & 11.46 \\
\hline 9 & 361303.1 & 7955971 & 361271.626 & 7956326.35 & 2.05 \\
\hline 10 & 361283.4 & 7955458 & 361264.192 & 7955849.15 & 13.3 \\
\hline 11 & 361650 & 7954903 & 361660.276 & 7955314.78 & 2.21 \\
\hline 12 & 361512 & 7954420 & 361533.434 & 7954875.93 & 14.81 \\
\hline 13 & 362103.4 & 7953586 & 362146.649 & 7954086.81 & 4.75 \\
\hline 14 & 362426.7 & 7953723 & 362469.924 & 7954163.45 & 10.52 \\
\hline 15 & 362970.7 & 7954194 & 362758.326 & 7954857.1 & 39.8 \\
\hline 16 & 361756.4 & 7955887 & 361749.562 & 7956199.31 & 14.28 \\
\hline 17 & 361500.2 & 7955732 & 361482.35 & 7956065.63 & 9.55 \\
\hline 18 & 362083.7 & 7955464 & 362090.859 & 7955798.55 & 0.6 \\
\hline 19 & 362075.8 & 7955756 & 362088.65 & 7956065.69 & 1.88 \\
\hline 20 & 362044.3 & 7956823 & 362021.218 & 7957020.07 & 4.04 \\
\hline 21 & 362075.8 & 7956519 & 362067.51 & 7956746.61 & 5.81 \\
\hline 22 & 362269 & 7956036 & 362359.208 & 7956409.32 & 15.34 \\
\hline 23 & 362777.6 & 7956299 & 362796.102 & 7956485.84 & 5.52 \\
\hline 24 & 362679 & 7956489 & 362691.472 & 7956657.51 & 6.57 \\
\hline 25 & 362884 & 7955523 & 362911.602 & 7955786.03 & 7.65 \\
\hline 26 & 362679 & 7955667 & 362705.575 & 7955932.18 & 1.41 \\
\hline 27 & 362765.7 & 7955214 & 362806.348 & 7955499.56 & 3.16 \\
\hline 28 & 362974.7 & 7954999 & 363030.548 & 7955289.79 & 0.79 \\
\hline 29 & 362970.7 & 7954194 & 363025.79 & 7954557.9 & 9.15 \\
\hline 30 & 363073.2 & 7953622 & 363156.171 & 7954010.79 & 2.37 \\
\hline 31 & 362919.5 & 7953211 & 362993.073 & 7953679.9 & 9.97 \\
\hline 32 & 363262.5 & 7954379 & 363324.554 & 7954698 & 1.51 \\
\hline 33 & 364437.3 & 7952734 & 364569.255 & 7953094.86 & 1.98 \\
\hline 34 & 364188.9 & 7955088 & 364280.912 & 7955270.84 & 3.87 \\
\hline 35 & 363849.9 & 7955410 & 363938.065 & 7955576.11 & 2.24 \\
\hline 36 & 364476.7 & 7955464 & 364576.272 & 7955582.67 & 1.44 \\
\hline 37 & 364890.7 & 7955613 & 365013.947 & 7955690.83 & 6.46 \\
\hline 38 & 364634.4 & 7955786 & 364732.594 & 7955881.69 & 11.34 \\
\hline 39 & 364346.6 & 7956072 & 364433.466 & 7956167.89 & 14.2 \\
\hline 40 & 364121.9 & 7956268 & 364190.407 & 7956358.76 & 3.37 \\
\hline 41 & 363664.6 & 7955619 & 363733.131 & 7955798.73 & 8.01 \\
\hline 42 & 363100.8 & 7956769 & 363137.232 & 7956873.85 & 3.83 \\
\hline 43 & 363230.9 & 7957318 & 363246.36 & 7957395.79 & 5.66 \\
\hline 44 & 363751 & 7956698 & 363798.919 & 7956772.19 & 8.96 \\
\hline 45 & 364255.9 & 7956912 & 364319.585 & 7956944.25 & 4 \\
\hline 46 & 364468.8 & 7956703 & 364537.12 & 7956727.8 & 5.7 \\
\hline 47 & 364528 & 7957151 & 364600.361 & 7957135.09 & 1.56 \\
\hline
\end{tabular}




$\begin{array}{clllll}\text { Puntos } & \text { X original } & \text { Y original } & \text { X corregido } & \text { Y corregido } & \text { Residual } \\ \mathbf{4 8} & \mathbf{3 6 4 0 9 0 . 4} & \mathbf{7 9 5 7 1 5 7} & \mathbf{3 6 4 1 3 9 . 5 3} & \mathbf{7 9 5 7 1 6 0 . 4 2} & \mathbf{1 0 . 5 1} \\ 49 & 364614.7 & 7957902 & 364667.483 & 7957809.47 & 6.04 \\ 50 & 364626.6 & 7958159 & 364683.816 & 7958032.22 & 7.61 \\ 51 & 363664.6 & 7958015 & 363684.839 & 7957987.62 & 1.72 \\ 52 & 364666 & 7958319 & 364717.463 & 7958172.2 & 1.91 \\ 53 & 364733 & 7958975 & 364770.771 & 7958770.43 & 4.68 \\ 54 & 364614.7 & 7959136 & 364646.795 & 7958923.1 & 1.09 \\ 55 & 362852.4 & 7959017 & 362821.967 & 7958967.11 & 7.27 \\ 56 & 363759.2 & 7959309 & 363759.89 & 7959158.19 & 3.46 \\ 57 & 363987.9 & 7959595 & 363991.024 & 7959400.01 & 0.87 \\ 58 & 363798.6 & 7959863 & 363780.473 & 7959673.54 & 1.97 \\ 59 & 363680.3 & 7960024 & 363662.568 & 7959820 & 2.46 \\ 60 & 363617.3 & 7960126 & 363601.118 & 7959921.64 & 0.6 \\ 61 & 363948.4 & 7960722 & 363931.214 & 7960437.14 & 3.55 \\ 62 & 363463.5 & 7960722 & 363420.197 & 7960487.98 & 1.76 \\ 63 & 363909 & 7961115 & 363879.81 & 7960799.64 & 4.76 \\ 64 & 363562.1 & 7961378 & 363511.375 & 7961073.18 & 1.32 \\ 65 & 363976.1 & 7961479 & 363941.796 & 7961124.17 & 4.35 \\ 66 & 363684.3 & 7962266 & 363618.349 & 7961868.65 & 1.27 \\ 67 & 363463.5 & 7962188 & 363396.575 & 7961811.14 & 6.1 \\ 68 & 363613.3 & 7961855 & 363562.123 & 7961486.89 & 0.56 \\ 69 & 363550.3 & 7962808 & 363481 & 7962370.98 & 0.33 \\ 70 & 363203.3 & 7958492 & 363199.617 & 7958458.16 & 6.35 \\ 71 & 362501.6 & 7957479 & 362491.082 & 7957586.31 & 1.12 \\ 72 & 362935.3 & 7953335 & 363030.975 & 7953764.66 & 2.33 \\ 73 & 362781.5 & 7952787 & 362858.51 & 7953278.38 & 1.88 \\ 74 & 362986.5 & 7953121 & 363077.215 & 7953570.9 & 1.51 \\ 75 & 362998.3 & 7953127 & 363083.776 & 7953589.34 & 4.55 \\ 76 & 362966.8 & 7953318 & 363035.973 & 7953762.16 & 8.22 \\ 77 & 362935.3 & 7953330 & 363028.163 & 7953763.1 & 2.26 \\ 78 & \mathbf{3 6 2 7 8 1 . 5} & 7953354 & \mathbf{3 6 2 8 4 1 . 6 3 9} & \mathbf{7 9 5 3 8 0 7 . 7 9} & \mathbf{1 1 . 5 2} \\ 79 & 363014.1 & 7953461 & 363089.088 & 7953882.8 & 9.11 \\ 80 & 360680.2 & 7956007 & 360649.59 & 7956415.46 & 2.18 \\ 81 & 360991.6 & 7956173 & 360947.029 & 7956522.96 & 1.14 \\ 82 & 361019.2 & 7956173 & 360972.024 & 7956542.97 & 7.73 \\ 83 & 361496.3 & 7956030 & 361459.423 & 7956370.45 & 3.28 \\ 84 & 364843.4 & 7955375 & 364954.328 & 7955507.27 & 3.66 \\ 85 & 364697.5 & 7955392 & 364806.859 & 7955488.52 & 2.25 \\ 86 & 364681.7 & 7955380 & 364806.859 & 7955488.52 & 2.12 \\ 87 & 364831.6 & 7955088 & 364948.704 & 7955222.88 & 6.07\end{array}$




\section{Cálculo de la altura de las edificaciones}

Basados en Cheng [6], podemos señalar que las alturas de los edificios pueden ser calculadas a partir del conocimiento de la longitud de la sombra que proyectan, del ángulo de elevación solar de la imagen, y de la pendiente del terreno. Sin embargo, para el caso de la ciudad de Arica, la pendiente es intrascendente para este cálculo, ya que la planicie donde se localiza no posee diferencias de altura significativas. Por esta razón, se procedió a calcular las alturas de las construcciones como se señala en la Fig.3.

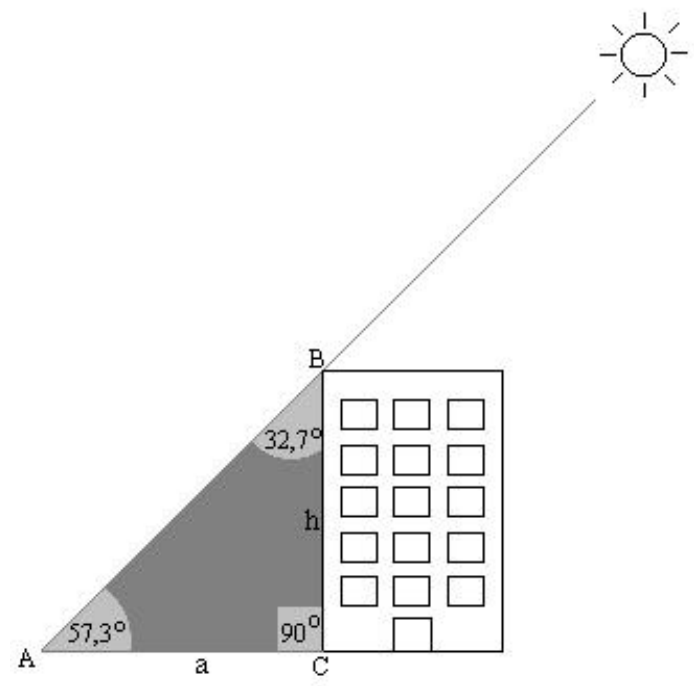

Fig.3.- Cálculo de altura de las construcciones

$$
\operatorname{tg} 57,3^{\circ}=h / a
$$

luego

$$
\begin{aligned}
& h=\operatorname{tg} 57,3^{\circ} * a \\
& h=0,54024 * a
\end{aligned}
$$

Donde:

- El ángulo de elevación solar que posee la imagen es de $57,3^{\circ}\left(57^{\circ} 18^{\prime}\right)$, según la información entregada por Space Imaging, empresa donde ésta fue adquirida.

- $\quad$ La longitud de la sombra (a), fue calculada a partir del número y tamaño del píxel (5 metros), en la columna central de la sombra proyectada por las edificaciones, debido a que ésta tiene menos interferencia que otras columnas. Así, para una sombra de 5 píxeles, la altura del edificio que la proyecta fue estimada en 13,51 metros.

Un problema complejo de solucionar, y que incide de manera negativa en el cálculo de las alturas de las construcciones mediante este método, se produce cuando las sombras de dos o más edificios se superponen, formando la denominada sombra de bloque, fenómeno que se manifiesta fundamentalmente en ciudades con barrios formados por bloques de edificios. Frente a esta situación, la ciudad de Arica tiene como una de sus características urbanísticas, el poco desarrollo de construcciones de altura, presentando la gran mayoría de los edificios un número inferior a los 5 pisos. Los que poseen alturas mayores, y que se han construido en los últimos 20 años, se localizan en zonas con un patrón constructivo bajo, por lo que estas edificaciones se presentan de manera aislada con respecto a su entorno, como se refleja en las Figs. 4, 5 y 6.

Lo anterior, pensamos que le otorga una mayor fiabilidad a los cálculos realizados, sustentados en la inexistencia de sombras de bloque, como consecuencia del carácter bajo de las construcciones, y en la distancia existente entre los distintos bloques de departamento de la ciudad.

El paso siguiente, una vez estimadas las alturas de las construcciones, consistió en otorgar un atributo de altura a los polígonos (manzanas) del mapa base de la ciudad, el que previamente fue generado mediante vectorización realizada sobre la imagen ya corregida. Sin embargo, debido a su extensión, algunos polígonos incorporan mas de una línea de construcción, por lo que se optó por dividirlos en función de este patrón homogéneo que es perceptible visualmente.

De esta forma, se generó el mapa de altura de las construcciones mediante el siguiente procedimiento:

- Se asignaron los valores de altura a cada polígono, mediante una planilla Excel que contiene los identificadores digitales de las manzanas de la ciudad.

- Esta matriz fue exportada al sistema de información geográfica (SIG) Idrisi, donde mediante el comando de asignación del gestor de base de datos, se generó un archivo que fue reclasificado en 7 intervalos, debido a que este número permite reflejar de manera más eficiente la distribución de los valores máximos y mínimos estimados, y a que no excede el total de categorías recomendables en un mapa.

- Se seleccionaron 20 polígonos sobre el mapa base, a través de la técnica de muestreo aleatorio estratificado, mediante el comando sample de Idrisi, que divide el área en matrices ortogonales de celdas y elige una localización aleatoria dentro de cada matriz.

- La verificación se realizó mediante trabajo de campo, con altímetros digitales de alta precisión, facilitados por el Ejército de Chile. El error promedio alcanzado fue de 1,5 metros. 
Uso de imágenes satelitales de alta resolución para generar cartografía

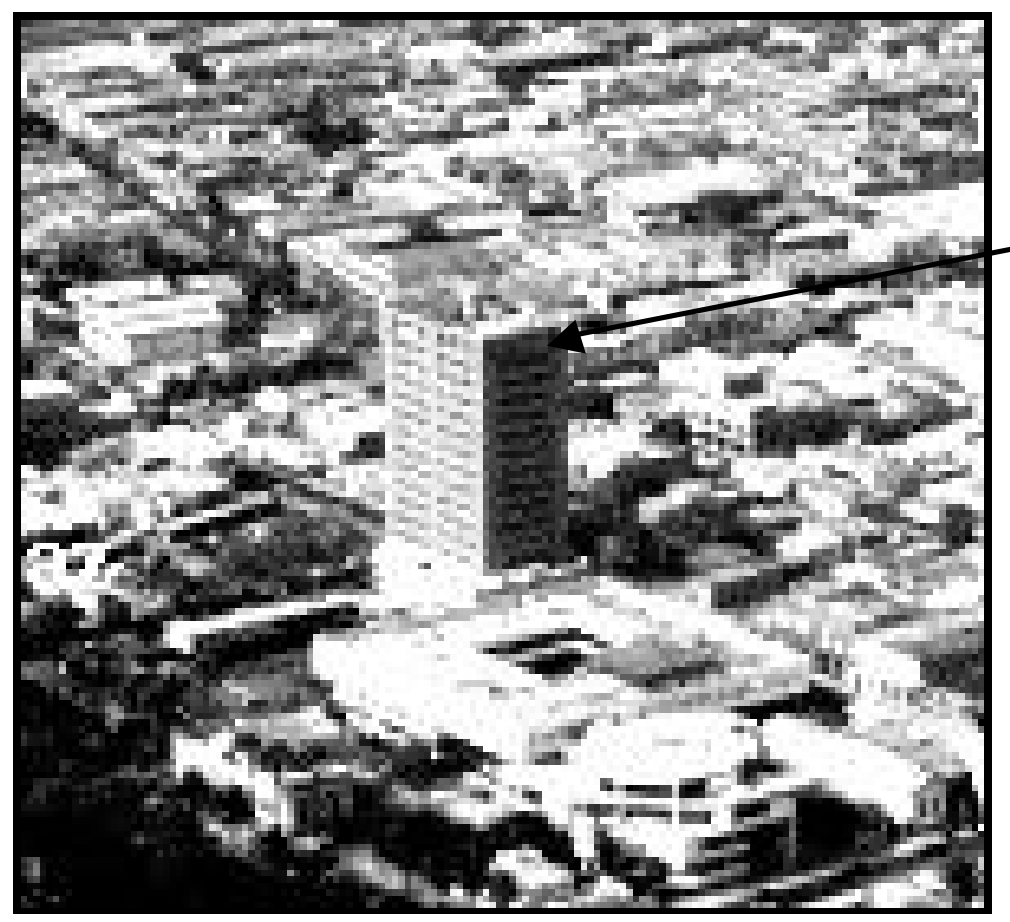

Edificio Empresarial.

Localizado en el centro de la ciudad, con 16 pisos de altura.

Fig. 4.- Edificio Empresarial (fuente: autores)

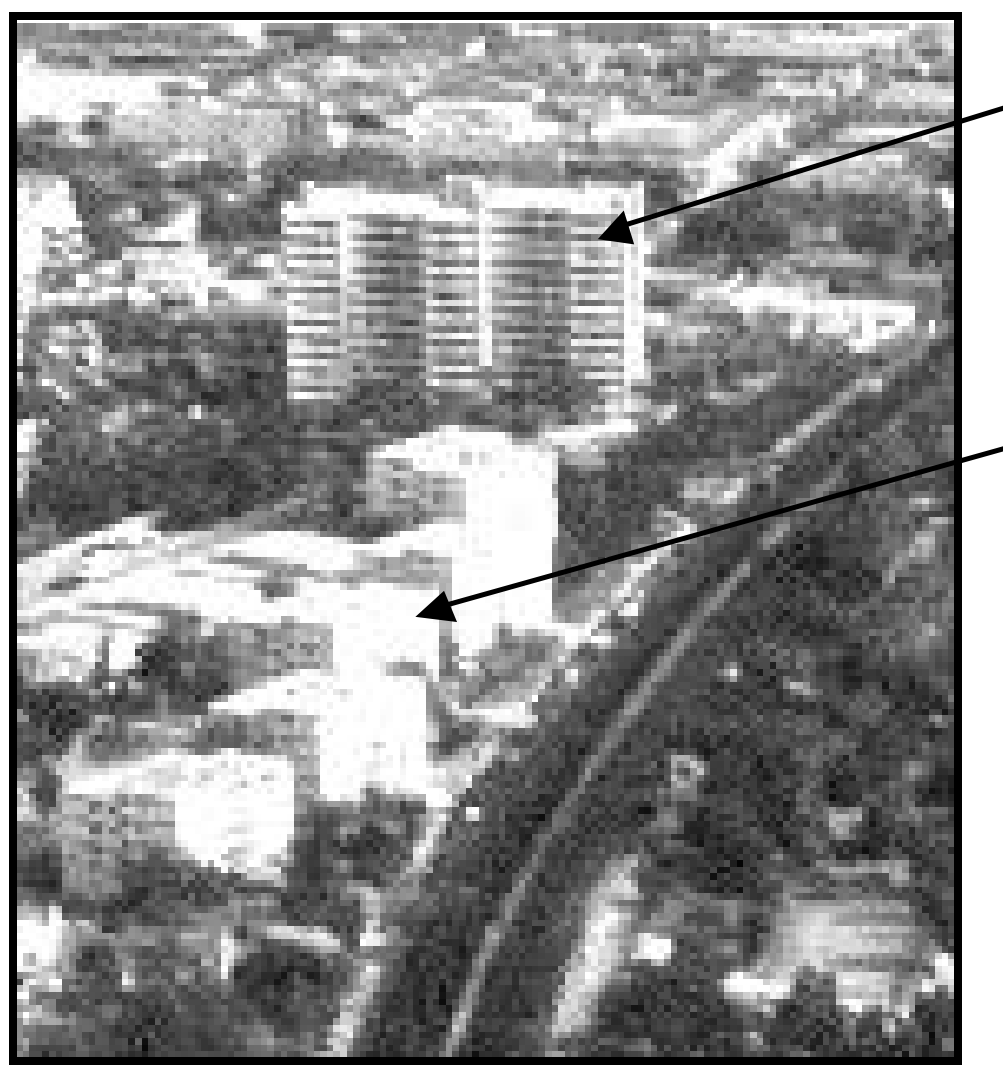

Edificio Ticnamar. Localizado en la periferia del centro de la ciudad, con un total de doce pisos de altura.

Edificios Chungará. Población de edificios uniformes, con 6 pisos de altura.

Fig. 5.- Edificio Ticnamar y su entorno (fuente: autores) 


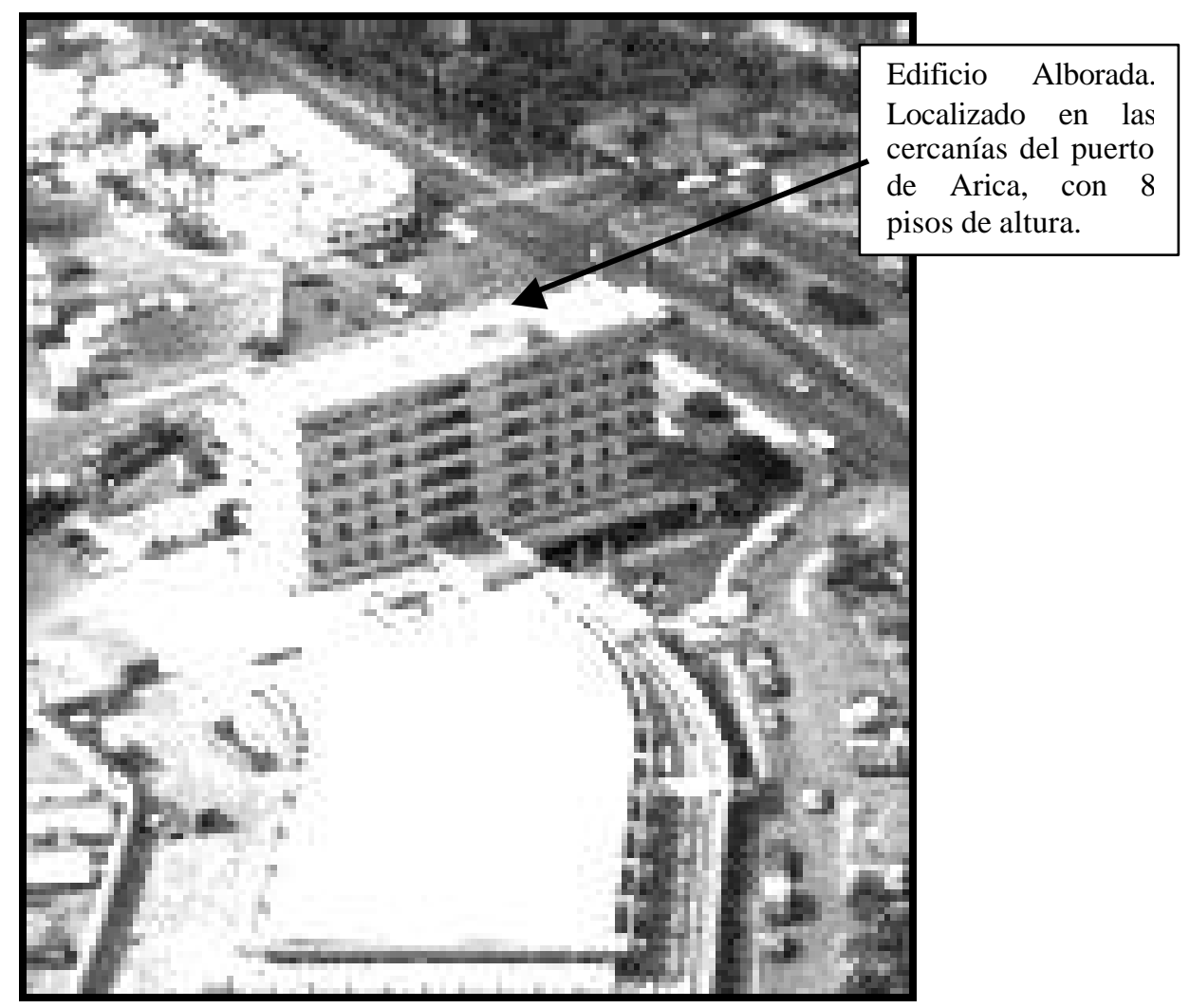

Fig. 6.- Edificio Alborada (fuente: autores)

\section{CONCLUSIONES}

El método aplicado, permitió responder de manera eficiente al requerimiento de una cartografía de alturas de la ciudad. Sin embargo, es importante señalar las dificultades que se presentan cuando las condiciones geomorfológicas y constructivas son diferentes.

En sectores con una geomorfología más compleja, las pendientes pueden presentar dificultades para una clasificación automatizada. En el caso de la ciudad de Arica, esta variable no se consideró por localizarse en una planicie litoral (Fase Concordia), con escaso desarrollo de pendientes. Sumado a esto creemos importante señalar el problema asociado con las denominadas sombras de bloque, que al presentarse en zonas de pendiente media debiesen aumentar el error de la estimación ostensiblemente.

Frente al problema de asignación de atributos de alturas a las manzanas, estimamos que la metodología aplicada, en cuanto a subdividirlas en polígonos homogéneos de construcción, permite solucionar de buena manera esta dificultad.
De la cartografía obtenida podemos señalar que la ciudad de Arica se caracteriza, al igual que muchas ciudades chilenas, por haber experimentado un crecimiento de tipo horizontal en desmedro de uno vertical. Esto queda demostrado en el mapa de la Fig. 7, en donde se puede apreciar que las edificaciones poseen en su gran mayoría, alturas que van de los 3 a los 6 metros, y que corresponden a viviendas unifamiliares de 1 y 2 pisos. Las edificaciones de mayor altura se localizan en la periferia del centro de la ciudad, en la calle Juan Noé, en torno a las poblaciones Ex Estadio y Chungará. En el centro se localizan sólo algunas construcciones de altura como el caso de los edificios Empresarial y Lan Chile. En la zona norte, las construcciones de mayor altura corresponden a las poblaciones Empart, Pucarani y Pedro Lagos, que son edificios DFL 2 de cuatro pisos, con alturas cercanas a los 15 metros. En el sector de Saucache destaca el conjunto de bloques de apartamentos conocidos como Parinacota, que son construcciones de 3 pisos con alturas que bordean los 13 metros. 


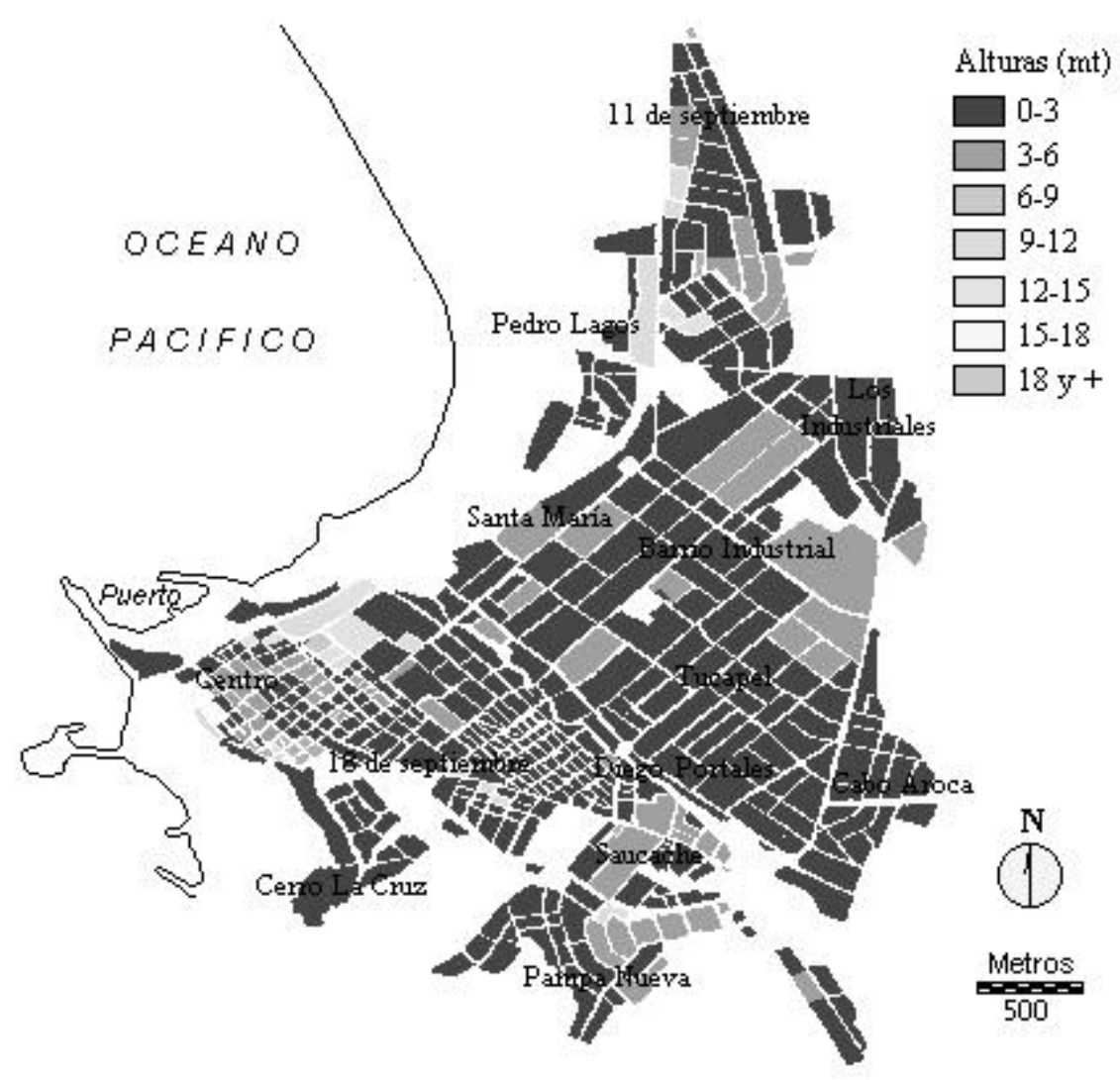

Fig. 7.- Distribución espacial de las alturas de la edificación

\section{REFERENCIAS}

[1] J. Blaikie; "At Risk: natural hazards, people's vulnerability, and disasters". Routledge Editores. Segunda Edición, Londres, 1994.

[2] A. Seaman; "Epidemiology of natural disasters". Basle Editores. Nueva York, 1984.

[3] M. Armand; "Teledetección, urbanismo y ordenamiento territorial". Cuadernos Pedagógicos del GDTA. Versión 1.0. Toulouse,1998.

[4] P. Zavala, E. Chuvieco; "Análisis de vulnerabilidad sísmica mediante Teledetección y S.I.G." Publicación de la Sociedad de Especialistas Latinoamericanos en Percepción Remota. Buenos Aires, 2000.

[5] E. Chuvieco; "Fundamentos de Teledetección espacial". Ediciones Rialp S.A. Tercera Edición revisada. Madrid, 1996.

[6] F. Cheng, K. Thiel; "Delimiting the building heights in a city from the shadow in a panchromatic Spot Image". En: International Journal of Remote Sensing. 16 (3): 409417. 